\title{
ACCOUNTING RESEARCH HOMOGENEITY AND THE POSSIBILITIES OF STRUCTURAL CHANGE
}

\author{
Brett R. Wilkinson \\ Baylor University \\ Chris H. Durden \\ James Cook University
}

\begin{abstract}
Concerns about the homogenization of accounting research have been expressed over an extended period of time, especially in the U.S. context. Numerous researchers have documented the homogeneity problem and examined the factors that have contributed to research homogeneity. One weakness in the current literature is that limited attention has been paid to understanding the process by which change might be effected. Although researchers have suggested specific changes in accounting academe that are warranted, there is no widely accepted theoretical framework within which proposals for reform can be analyzed. This may explain in part why there has been so little success in reversing the well documented homogeneity trend.

In this paper, we apply the theoretical framework developed by Dillard, Rigsby and Goodman (2004) in the managerial accounting context to understand the current research homogeneity problem and to demonstrate the changes that are necessary for lasting reform to occur. At the heart of the model is Giddens' (1976, 1979, 1981, 1984) notion of duality of structure. This duality of structure implies that the underlying rules that govern social behavior not only create resources but are themselves directly sustained by those same resources. Ultimately then, we suggest that if reform is to be successful, it will almost certainly necessitate a resource shift. In order to effect reform, the policy makers that control the resources by which the current structures shaping accounting research are sustained must act intentionally. There is evidence that such a resource shift precipitated the development of the current structure and it is unlikely that significant structural change can be achieved without a similar resource realignment.
\end{abstract}

